\title{
KEJADIAN EXCESSIVE DAYTIME SLEEPINESS (EDS) DAN KUALITAS TIDUR PADA MAHASISWA KESEHATAN
}

\author{
Desta Bambangsafira*, Tuti Nuraini \\ Fakultas Ilmu Keperawatan Universitas Indonesia, Depok 16424, Indonesia \\ *E-mail: destabambangsafira@gmail.com
}

\begin{abstract}
Abstrak
Kejadian Excessive Daytime Sleepiness (EDS) merupakan gejala yang timbul dari kecenderungan untuk merasakan kantuk yang berlebihan pada periode terjaga. Penelitian ini bertujuan untuk mengidentifikasi hubungan antara kejadian EDS dengan kualitas tidur pada mahasiswa baru di rumpun ilmu kesehatan. Desain penelitian ini adalah dengan pendekatan potong lintang menggunakan sampel mahasiswa Rumpun Ilmu Kesehatan sebesar 107 responden yang dipilih dengan teknik proportional stratified random sampling. Kejadian EDS diukur menggunakan kuesioner Epworth Sleepiness Scale (ESS), sedangkan kualitas tidur diukur menggunakan kuesioner Pittsburgh Sleep Quality Index (PSQI). Hasil penelitian menunjukkan bahwa prevalensi kejadian EDS dan kualitas tidur yang buruk cukup tinggi terjadi pada mahasiswa. Sebanyak 52 orang $(48,6 \%)$ mengalami EDS dan sebanyak 80 orang $(74,8 \%)$ memiliki kualitas tidur yang buruk. Hasil analisis statistik menunjukkan tidak ada hubungan yang signifikan $\left(\mathrm{p}=0,617: \mathrm{x}^{2}=0,249\right)$ antara kejadian Excessive Daytime Sleepiness dan kualitas tidur, sehingga perlu dilakukan penelitian lebih lanjut terkait faktorfaktor yang dapat memengaruhi kejadian EDS dan kualitas tidur. Selain itu, upaya promotif dan preventif dapat dilakukan untuk mencegah masalah kesehatan akibat kualitas tidur yang buruk.
\end{abstract}

Kata kunci: excessive daytime sleepiness, kualitas tidur, mahasiswa kesehatan

\begin{abstract}
The Incidence of Excessive Daytime Sleepiness and Quality of Sleeping in Health Students. Excessive Daytime Sleepiness $(E D S)$ is a symptom that arises from the tendency to feel excessive sleepiness during the awake period. This study aimed to identify the relationship between excessive daytime sleepiness and sleep quality among first year students at faculty of health sciences. This study used cross sectional design, involving 107 samples of students from the faculty of health science at University of Indonesia. Samples were selected by proportional stratified random sampling. EDS was measured by using Epworth Sleepiness Scale (ESS) while sleep quality was measured by using Pittsburgh Sleep Quality Index (PSQI). The results shows that the prevalence of EDS and poor sleep quality is high enough among college students. A total of 52 people (48.6\%) experienced EDS and as many as 80 people (74.8\%) had poor sleep quality. The result showed that there was no significant relationship $\left(p=0.617: x^{2}=0.249\right)$ between excessive daytime sleepiness and sleep quality, so further studies are required to identify factors affecting sleep quality or contributing to the incidence of EDS. This study recommended health promotion as a preventive effort to reduce the number of EDS and to increase students sleep quality.
\end{abstract}

Keywords: excessive daytime sleepiness, sleep quality, health students

\section{Pendahuluan}

Tidur merupakan sebuah proses biologis yang terjadi pada setiap individu. Tidur diperlukan oleh tiap individu untuk menjaga keseimbangan dirinya, baik dari segi kesehatan fisik, mental, maupun emosional. Kebutuhan tidur merupakan kebutuhan dasar yang terdapat pada tingkatan pertama hirearki Maslow (Potter \& Perry, 2009).

Kebutuhan tidur normal berbeda pada tiap individu. Selain kuantitas tidur, kualitas tidur yang baik juga perlu diperhatikan oleh tiap individu. Komponen kualitas tidur meliputi mutu tidur, latensi tidur/ waktu memulai tidur, 
durasi tidur, efisiensi tidur, gangguan tidur, penggunaan obat tidur, dan terganggunya aktivitas akibat masalah tidur (Buysse, Reynolds, Monk, Berman, \& Kupfer, 1989). Salah satu penyebab dari kualitas tidur yang buruk adalah Excessive Daytime Sleepiness (EDS). EDS merupakan sebuah gangguan neurologis yang menyebabkan rasa kantuk yang berlebihan di siang hari. Menurut National Sleep Foundation, EDS disebabkan oleh beberapa faktor seperti Obstuctive Sleep Apnea (OSA), insomnia, dan berbagai gangguan tidur lainnya.

Prevalensi tertinggi kejadian kantuk di siang hari yang berlebihan terjadi pada remaja, orang tua, dan pekerja shift (Pagel, 2009). Kantuk berlebihan di siang hari juga terjadi di kalangan mahasiswa. Sebuah penelitian mengidentifikasi 50\% mahasiswa mengalami EDS dan $70 \%$ mahasiswa mengalami tidur yang tidak adekuat (Hershner \& Chervin, 2014). Dampak dari kedua hal tersebut dapat memengaruhi kemampuan belajar, gangguan pada mood, dan kecelakaan kendaraan bermotor. Sebuah studi menyatakan bahwa 70\% mahasiswa mengalami kualitas tidur yang buruk (Hersner \& Chervin, 2014). Penelitian yang melibatkan 620 responden mahasiswa sarjana di Hong Kong, teridentifikasi $72,7 \%$ mahasiswa mengalami deprivasi tidur (Tsui \& Wing, 2009).

Mahasiswa merupakan kelompok usia yang memiliki stressor dan memengaruhi pola tidur di malam hari. Mahasiswa tingkat awal merupakan kelompok mahasiswa yang harus beradaptasi dengan lingkungan baru, temanteman baru, dan tanggung jawab baru. Studi menunjukkan bahwa banyak mahasiswa tahun pertama yang mengalami kesulitan dengan transisi dari SMA ke perguruan tinggi (Higher Education Research Institute UCLA, 2004; Kadison \& DiGeronimo, 2004; Sax, Bryant, \& Gilmartin, 2002 dalam Alipuria, 2007).

Data menunjukkan mahasiswa tahun pertama memiliki jam tidur yang lebih buruk dibandingkan dengan mahasiswa tahun ketiga dan keempat (Blank, 2015). Hal ini dapat disebab- kan oleh masa adaptasi dalam hal akademis. Oleh karena itu, pertanyaan yang diajukan adalah bagaimana gambaran kejadian EDS dan kualitas tidur dan hubungan antara kejadian EDS dengan kualitas tidur pada mahasiswa tahun pertama.

\section{Metode}

Penelitian ini menggunakan desain crosssectional yang dilakukan pada mahasiswa baru program sarjana reguler Rumpun Ilmu Kesehatan (RIK) pada bulan April-Mei 2016 dengan total responden sebanyak 107 orang. Pengambilan sampel dalam penelitian ini dilakukan dengan menggunakan probability sampling dengan teknik stratified random sampling.

Kuesioner terdiri dari 3 bagian, yaitu A untuk data demografi, B untuk mengukur kejadian Excessive Daytime Sleepiness (EDS), dan C untuk mengukur kualitas tidur. Epworth Sleepiness Scale (ESS) merupakan kuesioner yang digunakan untuk mengukur kejadian EDS. Sementara itu, Pittsburgh Sleep Quality Index (PSQI) merupakan kuesioner yang digunakan untuk menilai kualitas tidur responden. Kedua kuesioner tersebut kemudian akan diterjemahkan ke dalam Bahasa Indonesia dan hasilnya akan diukur sesuai dengan ketentuan baku yang berlaku.

Sebelum digunakan, kedua kuesioner tersebut telah diuji validitas dan reliabilitasnya pada 30 orang mahasiswa S1 Reguler angkatan 2015 Fakultas Ilmu Keperawatan Universitas X. Berdasarkan tabel nilai product moment, untuk jumlah responden sebanyak 30 orang dan taraf signifikansi yang diperlukan adalah 0,361. Hasil uji validitas pada kuesioner ESS menunjukkan bahwa semua item pertanyaan valid ( $\mathrm{r} \geq$ 0,361). Sementara itu, untuk kuesioner PSQI, terdapat 1 item pertanyaan yang tidak valid mengenai penggunaan obat tidur. Hasil uji reliabilitas kedua kuesioner tersebut, menunjukkan kedua kuesioner adalah reliabel untuk digunakan. 
Penelitian ini menggunakan analisis univariat dan bivariat. Analisis univariat digunakan untuk melihat persebaran dari data demografi, variabel independen, dan variabel dependen. Sementara itu, analisis bivariat digunakan untuk melihat hubungan antara kejadian EDS dan kualitas tidur. Analisis bivariat pada penelitian ini menggunakan uji Chi-Square.

\section{Hasil}

Hasil penelitian menjelaskan karakteristik usia responden. Nilai tengah usia responden adalah 18 tahun. Usia responden termuda 17 tahun dan usia tertua 20 tahun. Data karakteristik responden menunjukkan responden terbanyak berjenis kelamin perempuan $(77,6 \%)$, berasal dari Fakultas Kesehatan Masyarakat (FKM) (35, $5 \%)$, dan tinggal di asrama/kost $(53,3 \%)$.

Tabel 1 menunjukkan jumlah responden yang tidak mengalami EDS sedikit lebih banyak, yaitu sebesar $51,4 \%$. Tabel 2 menjelaskan distribusi frekuensi kejadian EDS dan karakteristik responden. Berdasarkan karakteristik jenis kelamin, perempuan menunjukkan hasil lebih banyak mengalami EDS dibandingkan dengan laki-laki. Karakteristik fakultas menunjukkan hanya Fakultas Ilmu Keperawatan (FIK) yang memiliki responden dengan jumlah yang mengalami EDS lebih banyak dibandingkan dengan yang tidak mengalami EDS. Sementara itu, karakteristik status tinggal menunjukkan bahwa responden yang tinggal di asrama/kost lebih banyak yang mengalami EDS dibanding dengan yang tinggal di rumah orang tua.

Tabel 3 menjelaskan distribusi frekuensi kualitas tidur responden secara umum. Responden dengan kualiltas tidur yang buruk berjumlah lebih banyak yaitu 80 orang $(74,8 \%)$ dan responden dengan kualitas tidur yang baik berjumlah 27 orang $(25,2 \%)$.

Tabel 1. Distribusi Frekuensi Kejadian EDS secara Umum

\begin{tabular}{lccc}
\hline & Variabel & Jumlah & Persentase \\
& & $(\mathbf{\%})$ & \\
\hline Kejadian EDS & & 52 & 48,6 \\
a. Mengalami EDS & & 55 & 51,4 \\
b. Tidak Mengalami EDS & Total & $\mathbf{1 0 7}$ & $\mathbf{1 0 0}$ \\
\hline
\end{tabular}

Tabel 2. Distribusi Frekuensi Kejadian EDS Berdasarkan Karakteristik Responden

\begin{tabular}{|c|c|c|c|c|c|}
\hline \multirow{3}{*}{ Variabel } & \multicolumn{4}{|c|}{ Kejadian EDS } & \multirow{3}{*}{ Total } \\
\hline & \multicolumn{2}{|c|}{ Mengalami EDS } & \multicolumn{2}{|c|}{ Tidak EDS } & \\
\hline & (n) & $(\%)$ & (n) & $(\%)$ & \\
\hline Jenis Kelamin & & & & & \\
\hline a. Laki-laki & 10 & 11,7 & 14 & 12,3 & 24 \\
\hline b. Perempuan & 42 & 40,3 & 41 & 42,7 & 83 \\
\hline Fakultas & & & & & \\
\hline a. FK & 9 & 11,2 & 14 & 11,8 & 23 \\
\hline b. FKG & 8 & 8,3 & 9 & 8,7 & 17 \\
\hline c. FIK & 12 & 8,3 & 5 & 8,7 & 17 \\
\hline d. FKM & 17 & 18,5 & 21 & 19,5 & 38 \\
\hline e. FF & 6 & 5,8 & 6 & 6,2 & 12 \\
\hline Status Tinggal & & & & & \\
\hline a. Asrama/ Kost & 32 & 27,7 & 25 & 29,3 & 57 \\
\hline b. Rumah Orang Tua & 20 & 24,3 & 30 & 25,7 & 50 \\
\hline
\end{tabular}



Tabel 3. Distribusi Frekuensi Kualitas Tidur secara Umum

\begin{tabular}{|c|c|c|}
\hline Variabel & $\begin{array}{c}\text { Jumlah } \\
\text { (n) }\end{array}$ & $\begin{array}{c}\text { Persentase } \\
(\%)\end{array}$ \\
\hline \multicolumn{3}{|l|}{ Kualitas Tidur } \\
\hline a. Kualitas Tidur Baik & 27 & 25,2 \\
\hline b. Kualitas Tidur Buruk & 80 & 74,8 \\
\hline Total & 107 & 100 \\
\hline
\end{tabular}

Tabel 4. Distribusi Frekuensi Kualitas Tidur Berdasarkan Karakteristik Responden

\begin{tabular}{|c|c|c|c|c|c|}
\hline \multirow{3}{*}{ Variabel } & \multicolumn{4}{|c|}{ Kualitas Tidur } & \multirow{3}{*}{ Total } \\
\hline & \multicolumn{2}{|c|}{ Baik } & \multicolumn{2}{|c|}{ Buruk } & \\
\hline & (n) & (\%) & (n) & $(\%)$ & \\
\hline Jenis Kelamin & & & & & \\
\hline a. Laki-laki & 10 & 6,1 & 14 & 17,9 & 24 \\
\hline b. Perempuan & 17 & 20,9 & 66 & 62,1 & 83 \\
\hline Fakultas & & & & & \\
\hline a. FK & 8 & 5,8 & 15 & 17,2 & 23 \\
\hline b. FKG & 8 & 4,3 & 9 & 12,7 & 17 \\
\hline c. FIK & 1 & 4,3 & 16 & 12,7 & 17 \\
\hline d. FKM & 6 & 9,6 & 32 & 28,4 & 38 \\
\hline e. FF & 4 & 3,0 & 8 & 9,0 & 12 \\
\hline Status Tinggal & & & & & \\
\hline a. Asrama/ Kost & 16 & 14,4 & 41 & 42,6 & 57 \\
\hline b. Rumah Orang Tua & 39 & 37,4 & 11 & 12,6 & 50 \\
\hline
\end{tabular}

Tabel 5 Distribusi Hubungan Kejadian EDS dan Kualitas Tidur

\begin{tabular}{|c|c|c|c|c|}
\hline \multirow[b]{2}{*}{ Variabel } & \multicolumn{2}{|c|}{ Kualitas Tidur } & \multirow[b]{2}{*}{ Total } & \multirow[b]{2}{*}{$\mathbf{p}$} \\
\hline & $\begin{array}{l}\text { Buruk } \\
\text { n }(\%) \\
\end{array}$ & $\begin{array}{c}\text { Baik } \\
\text { n }(\%)\end{array}$ & & \\
\hline Mengalami EDS & $40(37,4)$ & $12(11,2)$ & 52 & 0,617 \\
\hline Tidak Mengalami EDS & $40(37,4)$ & $15(14)$ & 55 & \\
\hline Total & $80((74,8)$ & $27(25,2)$ & 107 & \\
\hline
\end{tabular}

Tabel 4 menampilkan distribusi frekuensi kualitas tidur berdasarkan karakteristik responden. Berdasarkan karakteristik jenis kelamin, perempuan cenderung memiliki kualitas tidur yang buruk dibandingkan dengan laki-laki. Karakteristik fakultas menunjukkan bahwa tiap fakultas di RIK Universitas X memiliki jumlah responden dengan kualitas tidur yang buruk lebih banyak dibandingkan dengan responden yang memiliki kualitas tidur yang baik. Sementara itu, karakteristik status tinggal menunjukkan bahwa responden yang tinggal di asrama/ kost cenderung memiliki kualitas tidur yang buruk dibandingkan dengan responden yang tinggal di rumah orang tua.

Tabel 5 menunjukkan hasil analisis antara kejadian EDS dengan kualitas tidur. Uji statistik yang dilakukan yaitu uji Chi-Square. Berdasarkan hasil uji Chi-Square diperoleh nilai $\mathrm{p}$ sebesar 0,617 . Nilai $\alpha$ yang digunakan pada penelitian ini adalah 0,05 Hal ini menyatakan bahwa nilai $\mathrm{p}>$ nilai $\alpha\left(\mathrm{p}=0,617 ; \mathrm{x}^{2}=0,249\right)$ sehingga Ho diterima. Keputusan Ho diterima 
memberikan makna bahwa secara statistik tidak terdapat hubungan yang bermakna antara kejadian EDS dengan kualitas tidur pada mahasiswa baru program sarjana reguler RIK.

\section{Pembahasan}

Berdasarkan data karakteristik responden, usia responden berada pada rentang usia 17-20 tahun dengan rata-rata usia responden adalah 18,47 tahun dan nilai tengah 18 tahun. Rentang usia 17-20 tahun termasuk dalam kelompok usia remaja akhir (Potter \& Perry, 2009). Sebuah penelitian mengenai gangguan tidur pada mahasiswa juga menyatakan bahwa bahwa usia responden berada pada rentang 18-24 tahun (Thomas, 2014). Penelitian ini menunjukkan bahwa mahasiswa RIK telah sesuai dengan subjek penelitian yang dipilih, yaitu mahasiswa tahun pertama yang termasuk pada kategori kelompok usia remaja akhir.

Berdasar karakteristik jenis kelamin, jumlah responden didominasi oleh respoden perempuan. Dominasi proporsi jumlah perempuan di rumpun kesehatan pada sejumlah penelitian yang pernah dilakukan, sejalan dengan fakta bahwa profesi kesehatan lebih didominasi oleh perempuan karena diidentikan dengan kemampuan caring, tingkat kesabaran, ketelatenan, dan ketelitian yang lebih tinggi dibandingkan laki-laki (Pangesti, 2012). Penelitian lain di Pakistan juga mengatakan bahwa tingkat motivasi berdasarkan hierarki Maslow menunjukkan bahwa perempuan memiliki motivasi yang lebih tinggi untuk memasuki pendidikan kesehatan dibanding dengan laki-laki (Akhlaq \& Arouj, 2014).

Pada penelitian ini, dari total 140 orang respoden terdapat 77 orang responden (55\%) mengalami EDS. Prevalensi yang cukup besar pada kejadian EDS ini dapat dipengaruhi oleh beberapa faktor pada mahasiswa, seperti kelelahan fisik akibat aktifitas pada saat kuliah dan durasi tidur yang minim. Namun, terdapat perbedaan alat dan instrumen yang digunakan pada penelitian yang dilakukan kepada maha- siswa FKIK UIN Syarif Hidayatullah Jakarta. Selain menggunakan kuesioner ESS, penelitian yang dilakukan oleh Tubagus (2013) juga menggunakan Obstructive Sleep Apneal Hypopnea Syndrome Score (OSAHS score) dan pemeriksaan fisik. Berbagai faktor dapat memengaruhi kejadian EDS pada tiap individu. Sebuah penelitian yang dilakukan pada populasi multi etnik di Asia menunjukkan bahwa terdapat beberapa faktor yang dapat memengaruhi kejadian EDS, antara lain, perilaku tidur, jenis pekerjaan, dan faktor medis terkait perbedaan etnis yang signifikan (TP \& WC, 2005).

Pada penelitan ini, distribusi kejadian EDS berdasar karakteristik responden menunjukkan bahwa responden perempuan lebih banyak yang mengalami EDS. Hal ini terkait dengan gangguan tidur pada perempuan menyebutkan bahwa perempuan lebih cenderung memiliki keluhan tidur daripada laki-laki karena terjadinya perubahan hormon sepanjang rentang kehidupan seorang perempuan (Philips, Collop, Drake, Consens, Vgontzas, \& Weave, 2015). Penelitian lain terkait faktor risiko EDS dan kelelahan pada perempuan menyebutkan bahwa tekanan psikologis dan insomnia membuat perempuan lebih rentan mengalami kelelahan dan EDS (Haglow, Lindbergh, \& Janson, 2006).

Kualitas tidur mahasiswa pada penelitian ini cenderung memiliki kualitas tidur yang buruk. Penelitian lain yang membahas mengenai gambaran kualitas tidur pada mahasiswa program sarjana Universitas Indonesia melaporkan bahwa dari total 130 responden, sebanyak $81 \%$ responden mengalami kualitas tidur yang buruk (Windari,2013). Hal ini juga sejalan dengan penelitian yang dilakukan oleh Blank (2015) pada 312 responden mahasiswa tahun pertama Universitas Arizona. Penelitian ini memperoleh hasil bahwa terdapat 54\% mahasiswa memperoleh skor PSQI> 5. Hal ini mengindikasikan kualitas tidur yang buruk pada mahasiswa tahun pertama. Kualitas tidur yang buruk pada mahasiswa tahun pertama dapat disebabkan oleh perubahan ritme tidur - 
bangun antara masa sekolah menengah dengan masa perkuliahan. Mahasiswa cenderung memiliki tidur yang lebih singkat dan jam tidur yang lebih larut dibandingkan dengan kelompok populasi lain (Blank, 2015).

Kualitas tidur berdasar karakteristik responden menunjukkan bahwa responden perempuan cenderung mengalami kualitas tidur yang buruk. Kualitas tidur perempuan yang cenderung buruk, sangat dipengaruhi oleh suasana hati, rasa cemas, dan gejala depresi yang menyebabkan perempuan memiliki risiko $40 \%$ lebih besar untuk mengalami insomnia (Zhang \& Wing, 2006 dalam Mong, et al., 2011). Selain itu, responden yang tinggal di asrama/kost juga cenderung memiliki kualitas tidur yang buruk. Penelitian Edens (2006) mengenai hubungan antara kebiasaan tidur dengan motivasi akademik, bahwa terdapat hubungan status tempat tinggal mahasiswa dengan kualitas tidur. Mahasiswa yang tinggal di lingkungan kampus cenderung memiliki kualitas tidur yang buruk dibandingkan dengan mahasiswa yang tinggal di lingkungan luar kampus.

Hasil analisis statistik terkait dengan hubungan kejadian EDS dan kualitas tidur menunjukkan hasil bahwa tidak terdapat hubungan yang signifiikan antara kejadian EDS dan kualitas tidur pada mahasiswa baru program sarjana reguler RIK. Hal ini tidak sejalan dengan dua penelitian yang pernah dilakukan pada mahasiswa kedoteran di India dan Malaysia terkait dengan kejadian EDS dan kualitas tidur. Sebuah penelitian terkait dengan kebiasaan tidur dan masalah tidur pada mahasiswa kedokteran di Pravara Institute menyebutkan bahwa terdapat korelasi bermakna antara durasi tidur dan kejadian EDS ( $\mathrm{p}<0,001)$ (Giri, Baviskar, \& Phalke, 2013).

Perbedaan penelitian yang telah dilakukan peneliti dengan dua penelitian sebelumnya dapat dipengaruhi oleh berbagai faktor. Pada dua penelitian sebelumnya, terdapat perbedaan kuesioner yang digunakan. Selain itu, data demografi berupa BMI dan lifestyle (merokok, konsumsi alkohol, dan konsumsi kafein) juga merupakan dua komponen yang dapat menyebabkan perbedaan hasil dengan penelitian sebelumnya.

Sebuah penelitian mengenai validitas konstruk dan faktor struktur kuesioner PSQI dan ESS pada skala multi-nasional di Afrika, Asia Timur dan Amerika Selatan, menunjukkan perbedaan hasil dari kedua kuesioner tersebut (Gelaye, et al., 2014). Hasil penelitian tersebut menunjukkan bahwa etnis Malaysia dan China lebih rentan mengalami kejadian EDS dibandingkan dengan etnis India (TP \& WC, 2005). Selain itu, kedua kuesioner tersebut merupakan kuesioner yang penilaiannya bersifat subjektif tergantung pada interpretasi responden penelitian. Berdasarkan pengolahan data yang dilakukan, pada poin nomer 9 kuesioner PSQI, responden cenderung menilai kualitas tidurnya baik, padahal jika dihitung secara keseluruhan, sebagian besar responden memiliki kualitas tidur yang buruk (skor PSQI > 5).

Penilaian secara subjektif ini tentunya akan memengaruhi hasil analisis dari kedua kuesioner yang digunakan. Pada tabel 5 dapat terlihat bahwa terdapat jumlah yang sama besar antara responden yang mengalami EDS dan tidak mengalami EDS dengan kualitas tidur yang buruk. Selain merupakan masalah klinis, EDS juga merupakan masalah yang cukup banyak tersebar di masyarakat, dengan estimasi prevalensi setinggi $18 \%$. Banyak faktor yang berkontribusi terhadap kejadian EDS, meliputi kurang tidur kronis, sleep hygiene yang buruk, peningkatan BMI, peningkatan usia, dan variasi anatomi yang mempersempit saluran udara bagian atas. Namun, masih sulit untuk mengidentifikasi terkait faktor-faktor risiko yang siginifikan terhadap kejadian EDS (Slater \& Steir, 2012).

\section{Kesimpulan}

Berdasarkan hasil penelitian, dapat terlihat bahwa prevalensi kejadian EDS dan kualitas tidur yang buruk cukup tinggi terjadi pada 
mahasiswa tahun pertama rumpun ilmu kesehatan. Hasil analisis statistik menunjukkan tidak ada hubungan yang signifikan antara kejadian Excessive Daytime Sleepiness dan kualitas tidur, sehingga perlu dilakukan penelitian lebih lanjut terkait faktor-faktor yang dapat memengaruhi kejadian EDS dan kualitas tidur. Selain itu, upaya promotif dan preventif dapat dilakukan untuk mencegah masalah kesehatan akibat kualitas tidur yang buruk (JH, DG, TN).

\section{Referensi}

Akhlaq, B.A, \& Arouj, K. (2014). Study on the self esteem and strength of motivation of medical students. International Journal of Bussiness, Humanities and Technology, 4 (5), 58-63.

Alipuria, A.K. (2007). First-year college student decision making: How freshmen respond to the stress of the college transition (Order No. 3299567). ProQuest Dissertations \& Theses Global. (30487955). Diperoleh dari http:// search.proquest.com/docview/304879955/D3 0DD04C53844280PQ/1 ?accountid $=17242$

Blank, Y. (2015). The effects of changes in sleep schedule variability on first-year college student (Order No. 3713872). ProQuest Dissertations \& These Global. (17224762 39). Diperoleh dari http://search.proquest. com/docview/1722476239/7D6F8C6B32684 3FDPQ/1 ?accountid=17242

Buysse, D.J., Reynolds, C.F., Monk, T.H., Berman, S.R., \& Kupfer, D.J. (1989). The Pittsburgh sleep quality index (PSQI): A new instrument for psychiatric research and practice. Psychiatric Research, 28 (2), 193 213.

Edens, K.M. (2006). The relationship of university students sleep habits and academic motivation. NASPA Journal, 43 (3), 432-445.

Gelaye, B., Lohsoonthorn,V., Lertmeharit,S., Pensuksan, W.C., Sanchez, S.E., Lemma, S., Berhane, Y., Zhu,X., Velez, J.C., Barbosa, C., Anderade,A., Tadesse, M.G., Williams, M.A. (2014). Construct validity and factor structure of the pittsburgh sleep quality index and epworth aleepiness scale in a multinational study of African, South East Asian and South American College Students. PLoS ONE, 9 (2), e116383. https://doi.org/10.137 1/journal.pone. 0116383

Giri, P.A., Baviskar, M.P., \& Phalke, D.B. (2013). Study of sleep habits and sleep problems among medical students of Pravara Institute of Medical Sciences Loni, Western Maharashtra, India. Annals of Medical and Health Sciences Research, 3 (1), 51-54.

Haglow, J.T., Lindberg, E., Janson, C. (2006). What are the important risk factors for daytime sleepiness and fatigue in women? Sleep, 29 (6).

Hershner, S.D., \& Chervin, R.D. (2014). Causes and consequences of sleepiness among college students. Nature and Science of Sleep, 6, 73-84.

Mong, J.A., Baker, F.C., Mahoney, M.M., Paul, K.N., Schwartz, M.D., Semba, K., Silver, R. (2011). Sleep, rhythms, and the endocrine vrain: Influence of sex and gonadal hormones. The Journal of Neuroscience, 31 (45), 16107-16116. doi: 10.1523/JNEURO SCI.4175-11.2011

Pagel, J.F. (2009). Excessive daytime sleepiness. American Family Physician, 79 (5), 391396.

Pangesti, A.D.H. (2012). Gambaran tingkat pengetahuan dan tingkat aplikasi kesiapan bencana pada mahasiswa Fakultas Ilmu Keperawatan Universitas Indonesia (Skripsi, tidak dipublikasikan). Fakultas Ilmu Keperawatan Universitas Indonesia, Depok.

Philips, B.A., Collop, N.A., Drake, C., Consens, F., Vgontzas, A.n., Weaver, T.E. (2008). Sleep disorders and medical conditions in women. Journal of Womens Health. doi: 10.1089/jwh.2007.0561.

Potter, P.A \& Perry, A.G. (2009). Fundamental of nursing (7th Ed.). (Terjemahan). Jakarta: Salemba Medika 
Slater, G., \& Steier, J. (2012). Excessive daytime sleepiness in sleep disorders. Journal of Thoracic Disease, 4 (6), 608-616. doi: 10.3978/j.issn.2072-1439.2012.10.07.

Thomas, S.J. (2014). a survey of sleep disorders in college students: A study of prevalence and outcomes (Order No. 3639271). ProQuest Dissertations \& These Global. (1619605 802). Diperoleh dari http://search.proquest. com/docview/1619605802/D3270C3607424 EEBPQ/1?accountid=17242.

TP, N., \& WC, T. (2005). Prevalence and determinants of excessive daytime sleepiness in an Asian multi-ethnic population. Sleep Medicine, 6 (6), 523-529.

Tsui, Y.Y., \& Wing, Y.K. (2009). A study on the sleep patterns and problems of University
Business Students in Hong Kong. Journal of American College Health, 58 (2), 167-176. doi: 10.1080/07448480903221418.

Tubagus, N.E.N. (2013). Prevalensi excessive daytime sleepiness (EDS) pada mahasiswa FKIK UIN Syarif Hidayatullah Jakarta dengan menggunakan kuesioner epworth sleepiness scale (ESS) serta faktor risiko yang mempengaruhinya pada tahun 2013 (Skripsi, tidak dipublikasikan). FKIK UIN Syarif Hidayatullah, Jakarta.

Windari, H. (2013). Hubungan gambaran kualitas tidur mahasiswa Program Sarjana Universitas Indonesia (Skripsi, tidak dipublikasikan). Fakultas Ilmu Keperawatan Universitas Indonesia, Depok. 